\title{
Pedagogical Ninjas: Using an Additive Innovation Cycle for Faculty Devel- opment of Teaching-focused Faculty
}

Hadi Ali, Arizona State University, Polytechnic campus

Hadi Ali is a doctoral student in Engineering Education Systems and Design at Arizona State University.

\section{Dr. Jennifer M. Bekki, Arizona State University}

Jennifer M. Bekki is an Associate Professor in The Polytechnic School within the Ira A. Fulton Schools of Engineering at Arizona State University. Her research interests include topics related to engineering student persistence, STEM graduate students (particularly women), online learning, educational data mining, and the modeling and analysis of manufacturing systems. She holds a bachelor's degree in Bioengineering and graduate degrees in Industrial Engineering, all from Arizona State University.

\section{Dr. Samantha Ruth Brunhaver, Arizona State University}

Dr. Samantha R. Brunhaver is an Assistant Professor within The Polytechnic School, one of six schools in the Ira A. Fulton Schools of Engineering at Arizona State University. She is a mixed-methods researcher with focus on the preparation and pathways of engineering students. Her specific research interests include engineering student persistence and career decision-making, early career engineering practice, faculty pedagogical risk-taking, and entrepreneurial mindset. She completed her B.S. in Mechanical Engineering at Northeastern University and her M.S. and Ph.D. in Mechanical Engineering at Stanford University. Prior to ASU, she worked as an engineer at A. W. Chesterton, Boston Scientific, and Procter \& Gamble.

\section{Dr. Shawn S. Jordan, Arizona State University, Polytechnic campus}

SHAWN JORDAN, Ph.D. is an Associate Professor of engineering in the Ira A. Fulton Schools of Engineering at Arizona State University. He teaches context-centered electrical engineering and embedded systems design courses, and studies the use of context in both K-12 and undergraduate engineering design education. He received his Ph.D. in Engineering Education (2010) and M.S./B.S. in Electrical and Computer Engineering from Purdue University. Dr. Jordan is PI on several NSF-funded projects related to design, including an NSF Early CAREER Award entitled "CAREER: Engineering Design Across Navajo Culture, Community, and Society" and "Might Young Makers be the Engineers of the Future?," and is a Co-PI on the NSF Revolutionizing Engineering Departments grant "Additive Innovation: An Educational Ecosystem of Making and Risk Taking." He was named one of ASEE PRISM's "20 Faculty Under 40" in 2014, and received a Presidential Early Career Award for Scientists and Engineers from President Obama in 2017.

\section{Dr. Micah Lande, South Dakota School of Mines \& Technology}

Micah Lande, Ph.D. is an Assistant Professor and E.R. Stensaas Chair for Engineering Education in the Department of Mechanical Engineering at the South Dakota School of Mines \& Technology. He teaches human-centered engineering design, design thinking, and design innovation courses. Dr. Lande researches how technical and non-technical people learn and apply design thinking and making processes to their work. He is interested in the intersection of designerly epistemic identities and vocational pathways. Dr. Lande received his B.S. in Engineering (Product Design), M.A. in Education (Learning, Design and Technology) and Ph.D. in Mechanical Engineering (Design Education) from Stanford University. He was previously an Assistant Professor in the Engineering and Manufacturing Engineering programs and Tooker Professor for Effective STEM Education at the Polytechnic School in the Ira A. Fulton Schools of Engineering at Arizona State University. 


\title{
Pedagogical Ninjas: Using an Additive Innovation Cycle for Faculty Development of Teaching-Focused Faculty
}

\begin{abstract}
This evidence-based, practice paper describes a semester-long, faculty development program designed by an "additive innovation" [1] framework to promote the sharing, scaling, sustainability, and implementation of a pedagogical risk-taking culture across a school of engineering. This intervention has been developed as part of a research project that is funded by the National Science Foundation "Revolutionizing Engineering and Computer Science Departments" (RED) program [2]. The structure of the faculty development program is described, focusing on practical strategies that were found effective in guiding the interventions. Fifteen participants engaged in a series of structured events to design and implement their own pedagogical innovations in their classroom during the semester of Fall 2018. The paper describes the events that took place in the program, shares lessons learned, and highlights future work to analyze the data collected from the activities further.
\end{abstract}

\section{Introduction}

Faculty, as active agents for change in the classroom, are essential in transforming engineering education for students and also for their fellow faculty. An ability to impact students directly brings a critical component for systematic change in higher education. In this paper, the authors present pedagogical risk-taking as a key component in the described faculty development program to cultivate and guide an innovation process in academia. Pedagogical risk-taking is operationalized as faculty's willingness to trying pedagogical approaches on their own, in the classroom, for which the outcome is unknown [2]. The set of activities and interventions to support this pedagogical risk-taking is guided by an additive innovation framework which presents a set of design principles that participants in a community exhibit when collaborating within the community [1]. Building on previous research in the Maker community, the research team used the four stages identified in the additive innovation cycle as a roadmap to organize faculty professional development activities to promote pedagogical risk-taking: (1) becoming inspired by their community, (2) sharing and learning about pedagogical ideas and artifacts, (3) iterating on their own pedagogical ideas and artifacts, and (4) sharing the results of their pedagogical innovations back into the community [1]. It was hypothesized that, through these steps, the process would empower faculty to be agents of change while creating a community that values the additive innovation mindset. The intervention took place during the Fall 2018 semester, with a cohort of fifteen instructors from within a general engineering program at a large public university in the southwest. This paper describes the logistics and structure for the faculty development program. Future work will dive into the collected data for analysis.

\section{Background}

Calls to transform engineering education have emphasized the importance of preparing engineering students for the evolving nature of engineering practice [3]. For example, the National Academy of Engineering Engineer of 2020 report [4] has provided a guiding light for 
engineering education over the last decade with a series of recommendations meant to better equip engineering students for what professional engineering practice was expected to look like. More recently, the National Science \& Technology Council's report entitled Charting a Course for Success: America's Strategy for STEM Education similarly describes STEM education as an ecosystem with purpose to shape engineering students to meet the demands driven by changing workforce demographics and needs [5]. From this increased focus on the preparation of engineering students for professional success has come a corresponding emphasis on pedagogical change and innovation in engineering education, particularly at the college level.

Pedagogical change within higher education is often promoted through traditional means of dissemination such as professional development workshops [6]. These interventions can be limited in that they are singular, administratively driven, and individually focused, and therefore, they are not always effective at inspiring cultural change. Other strategies for change have taken more non-traditional approaches toward pedagogical reform [7, 8, 9], such as by shifting the focus from imposing organizational structure to understanding individual motivations and behaviors $[10,11]$. In this view, "better understand[ing] what motivates faculty to act within the system" [12, p. 303] can help catalyze faculty to become agents for change.

New trends in engineering education have also shifted focus away from being teacher-centered to being learner-centered [13], and in doing so, have led to the development of faculty-led learning communities [14] committed to sharing successful models of student engagement and evidence-based innovation. Such models of development-and-dissemination are widely used to transform undergraduate instruction [15] and demonstrate that successful implementation in one educational context can be transferred to another with potential for similar success $[16,17]$.

A report by the American Society of Engineering Education (ASEE), Creating a Culture for Scholarly and Systematic Innovation in Engineering Education, endorses the creation of such a culture for scholarly and systematic innovation within engineering education [18]. The report conceptualizes innovation in engineering education as intentionally engaging the faculty in a cycle that reciprocates between "research" and "practice". The authors write, "In an instantiation of the model, and practitioners, potentially from multiple fields and organizations, collaborate from the outset in framing, designing, implementing, evaluating, and disseminating an educational innovation" [p. 6].

Collectively, these various strategies for change have served as inspiration for the Pedagogical Ninjas program in which both aspects of professional development and the model of development-and-dissemination are utilized in an additive innovation cycle (Figure 1).

Additive innovation is a community-driven process wherein participants within the community engage each other in the following four steps.:

- Inspiring a community of innovators: In this step, a collection of ideas, resources and suggestions inspires members of the community to share stories of both successes and failures. The end result of this step is both "to inspire and be inspired" [1].

- Sharing and learning of how "it" was made: After the inspiration phase, openly sharing knowledge, artifacts and processes allows members to engage in a learning experience 
[1]. This step involves the wider spread of knowledge and best practices within the community.

- Iterating to create new innovations: Active engagement within the community enables the use of shared knowledge and resources to make anew. "Through additively building on the work of others," a combination of a sense of collaboration and a sense of confidence is diffused within the community, allowing members to both share and seek advice in an iterative process to create new designs [1].

- Sharing improved innovations back with the community: Completing the cycle (and reinitiating it) is the sharing of stories of the improved innovations "to push the collective understanding" [1].

The reason why the additive innovation was chosen is because the additive innovation mindset, stemming from observing characters of the Maker community, promotes the behavior of openness and sharing within the community [1]. Compared to traditional cycles of continuous improvements, the additive innovation cycle emphasizes the empowerment for faculty to be agents of change while creating a community that values the additive innovation mindset.

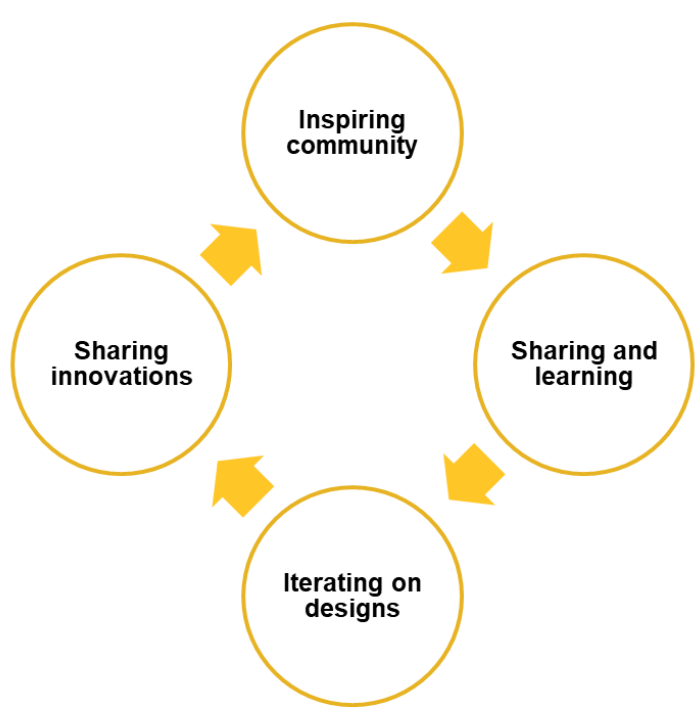

Figure 1. Additive innovation cycle [1].

\section{Research Design Considerations and Study Aims}

In a precursory study that developed a framework to encourage pedagogical risk-taking among faculty [2], the research team developed a set of guiding principles to evaluate interventions aimed at revolutionizing engineering departments. According to these guiding principles, faculty-based interventions should be "based on faculty-driven (vs. administration-driven) ideas;" "community (versus individually) focused;" and "sustained in duration" (i.e., not a oneoff event). In this study, a multiple case study approach is employed to investigate the effectiveness and impact of a program designed with these principles in mind. We are specifically interested in understanding how participation in each stage of an additive innovation cycle influences faculty practices and intentions related to pedagogical risk-taking.

In this study, we engaged a cohort of non-tenure line instructors in a range of pedagogical interventions (named the Pedagogical Ninjas program) that spanned one semester following the design principles of the additive innovation cycle. We intentionally chose to focus on this population to create a close-knit, coherent community of uniform rank and shared perspective on the importance of teaching. Data was collected from each faculty participant, in the form of the 
artifacts they created, surveys, and reflective interviews. In this paper, we present details about each stage of the additive innovation cycle, including its corresponding activities and materials. The work described in this paper focuses on the structure, implementation, and deployment of this faculty development program.

\section{Intervention Design and Descriptions}

One of the unique aspects of the Pedagogical Ninjas program is the intensive cycle of research design, activity planning, and data collection that occurred between May and December 2018. This model was influenced by the aforementioned ASEE report which proposes an innovation cycle adapted from Booth, Colomb, and Williams [19] that "outlines a continual flow between practice and research and between research and practice" [18, p. 6]. However, within the ASEE report, the disconnect between research and practice was made clear: "The clear message is that all arcs in the model need attention" $[18$, p. 6]. Our implementation utilizes the additive innovation cycle as an accelerated, enhanced framework to connect education innovation with practice. In the discussion below, the parallel evolution of research design with the development and implementation of program activities is discussed.

\section{Initial planning (Summer 2018)}

Early planning for the Pedagogical Ninjas program started in May 2018. Key decisions had to be made surrounding the program design and activities. This involved formalizing the research questions guiding the study, developing the study timeline, developing research tools to assess the efficacy of each activity, identifying participants, developing recruitment strategies, planning activities to support the additive innovation cycle, and creating a "brand" for the program. Another key decision was identifying the available budget for the project and the best way to effectively use the available resources. During the summer, we also obtained approval for the study from the Institutional Review Board.

To identify participants, and in order to design program a program suitable for their needs, understanding faculty needs was achieved through customer discovery interviews with potential participants (see [20]). In addition, ideas from NSF's initiative, Innovation Corps Teams Program: I-Corps for Learning (I-Corps L) [21], the Lean Launchpad [22], as well as the Business Model Canvas (BMS) were utilized. Participant recruitment was focused on faculty members with teaching-focused appointment (i.e., not tenured or tenure-track faculty). Potential participants were invited via email to participate, and an incentive of $\$ 2,000$ in supplemental pay was offered as compensation for completing the program. Table 1 shows the list of activities that were planned for each phase of the additive innovation cycle, including whether they were considered mandatory for complete participation.

Parallel with the planning of the logistics of the program, key research design decisions were made during the summer. This involved deciding on potential methodologies, with case study research [23] emerging as the most suitable for the study because it addresses the explanatory "how" nature of the research question driving this study. In addition, the centrality of the faculty as key participants in this study is also highlighted in the case study method. Separately, the research team also had discussions about the definition of risk in this study. It was decided that, 
when characterizing the risk being taken by faculty in their chosen interventions, risk would be viewed from the perspective of the faculty member, i.e., the risk-taker, as opposed to risk being externally judged or assessed.

Table 1. Schedule of events as presented during the kickoff meeting.

\begin{tabular}{llll}
\hline $\begin{array}{l}\text { Additive Innovation } \\
\text { Phase }\end{array}$ & Month & Event $(s)$ & Attendance \\
\hline Inspiring Community & August & Kickoff meeting & required \\
\cline { 2 - 4 } Sharing \& Learning & September & Teaching and pedagogy workshops & $\begin{array}{l}\text { attend } 2 \text { of } 4 \\
\text { sessions }\end{array}$ \\
\hline Iterating on Designs & October & Teaching hackathon sessions & $\begin{array}{l}\text { attend 1 of } 2 \\
\text { sessions }\end{array}$ \\
\cline { 2 - 4 } optional (2 events) \\
\hline Sharing Innovations & December & REDtalks story crafting workshop & required \\
\hline
\end{tabular}

After choosing a case study research method, the research team developed data sources with which to study each phase of the additive innovation cycle. Early choices centered on surveys, interviews, document analysis and artifact elicitation. Surveys included demographic questions and items from a pedagogical risk-taking instrument, with the purpose to support qualitative data obtained from the interviews. Interviews were reflective in nature, tracking participants' changes in mindset and interest related to pedagogical risk-taking as they engaged in the range of pedagogical interventions comprising the additive innovation cycle. Overall, the use of multiple sources of evidence in the data collection process was considered crucial in helping establish the chain of evidence necessary for the case study research design.

Formal events were scheduled to take place on early Friday afternoons when all participants were available. An exception was a day-long, end-of-semester workshop that took place after final exams had concluded. Recognizing the demanding nature of the program, as well as the additional time required by the participants to plan and implement their chosen interventions during the semester, participants were required to attend only up to two events per month, with informal check-ins and optional community building happy hours taking the place of formal meetings in November. We provide next details about each of the events in the Pedagogical Ninjas program.

\section{Kickoff event (August)}

This event was designed as a welcoming event to introduce participants to the program and related expectations, the additive innovation cycle, and the schedule. The mapping between stages of the additive innovation cycle and the events of the program was also made explicit, and participants were encouraged to ask questions about participation. Following questions and answers, consent forms were distributed to be completed by faculty committed to participating in the program. The kickoff event took place on a Friday afternoon and included lunch. 


\section{Lightning Round Presentations (August)}

The lightning round event was designed as the first step in the additive innovation cycle, Inspiring Community. During the event, each attendee shared a teaching innovation that they'd previously implemented one of their classes. Along with requiring all Pedagogical Ninja participants to attend, an open invitation was sent to all faculty within the academic unit, expanding participation and the number of innovations shared. Five other faculty members joined the event in response to the invitation. Faculty were encouraged to ask questions, give feedback, and exchange ideas.

To facilitate the event, a reminder email was sent one week prior. The email contained a live link to a Google slide deck to which each participant could add slides about their innovation. This process was facilitated by a slide at the beginning that included instructions for how to add slides in addition to guidelines for how to populate the slides. It was recommended, for example, that each participant add three slides, covering information about the class context ("Share the context of what you are doing as an activity or innovation."), their teaching innovation ("How does it work?"), and advice for implementation ("Share your advice on making this activity or innovation work well."), and that they budget three minutes for presenting. The provided deck of slides also included example innovations from the research team. Two example innovations shared by Pedagogical Ninjas participants are shown in Figure 2.
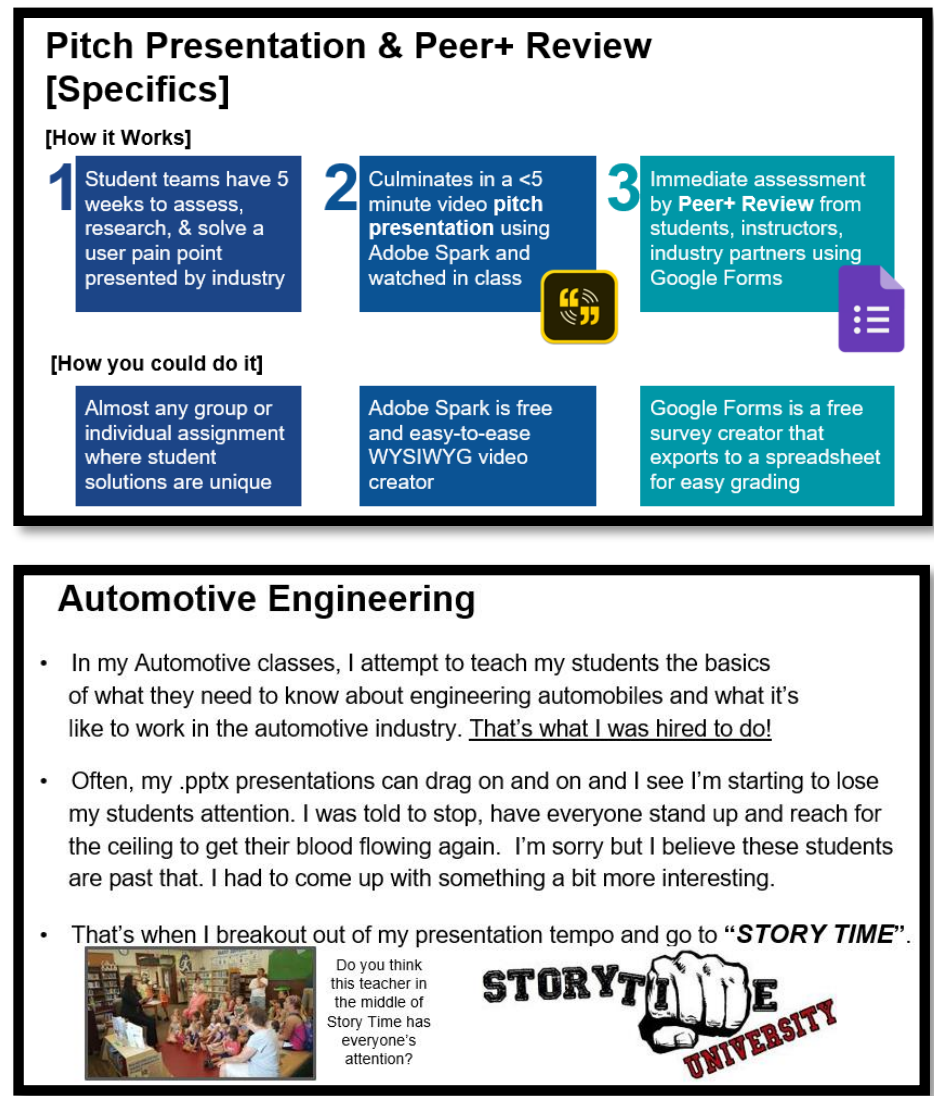

Figure 2. Examples of innovations shared by two instructors during the lightning round event as part of the "Inspiring the Community" phase of the additive innovation cycle. 
A list of all topics presented by Pedagogical Ninja participants during the lightning round event is provided in Table 2, with pseudonyms used in place of actual participant names. As shown, some presented ideas that were highly relevant to their disciplines, context-specific, and left it to their audience to make the connections, while others were describing pure pedagogical interventions. Overall, initial feedback indicates the Lightening Round event was viewed as useful and enjoyable by Pedagogical Ninja participants. In the first reflective interview, participant Betty (pseudonym) described her experience as follows, "So far, I liked the lightning round where we had three minutes to talk about something that we were doing." Similarly, participant Nat (pseudonym) provided the following comment on the event, "Fantastic. I love the fact that we have so much freedom to craft ideas."

Table 2. Innovation presented by each participant during the lightning round event.

\begin{tabular}{lll}
\hline $\begin{array}{l}\text { Participant } \\
\text { (Pseudonym) }\end{array}$ & $\begin{array}{l}\text { Teaching } \\
\text { domain }\end{array}$ & Innovation \\
\hline Alexander & Entrepreneurship & Real-world team projects at scale \\
\hline Betty & Graphics & Peer review \\
\hline Craig & Automotive & Storytelling \\
\hline Derek & Media & Three-pronged incorporation of social media tools \\
\hline Ed & Graphics & Micro-assignments that scale \\
\hline Felicia & Programming & Experiential learning \\
\hline Griffin & Design & Partnering with schools to provide engineering solutions \\
\hline Hannah & Graphics & Solution videos available two days after due date \\
\hline Ian & Economics & Turning homework into a semester-long game \\
\hline Julia & Design & Brainstorming as part of the design process \\
\hline Kayla & Photography & Making projects relevant to students \\
\hline Lucas & Graphics & Allowing students to choose their own project \\
\hline Matt & Environmental & Partnering with outside government collaborators \\
\hline Nate & Entrepreneurship & Incorporating graphics into slides \\
\hline Olivia & Air traffic control & Adding stories, pictures and video clips to lab time \\
\hline
\end{tabular}

\section{Teaching Workshops (September)}

As part of the second phase of the additive innovation cycle, Sharing \& Learning, participants were asked to attend at least two of four professional development workshops focused on pedagogy. Workshops were offered on a range of topics to appeal to the different teaching experiences and teaching domains of the participants. We used Teaching and Learning STEM: A Practical Guide by Felder and Brent [6] to guide the selection of workshop topics and then identified different speakers and workshop formats to pair with each topic. Participants were asked to identify their top two choices from a given list.

The workshop topics and formats shown in Table 3 were ultimately implemented, with each workshop offered in a different week. The content of each workshop is described below. 
Table 3. Schedule of workshops.

\begin{tabular}{cll}
\hline Workshop & \multicolumn{1}{c}{ Topic } & \multicolumn{1}{c}{ Format } \\
\hline 1 & $\begin{array}{l}\text { Technology and classroom } \\
\text { innovation / active learning }\end{array}$ & $\begin{array}{l}\text { In-person workshop facilitated by university } \\
\text { colleagues from the "Just in Time Teaching } \\
\text { with Two-Way Formative Feedback" project }\end{array}$ \\
\hline 2 & $\begin{array}{l}\text { Active learning / classroom } \\
\text { management }\end{array}$ & $\begin{array}{l}\text { Workshop facilitated virtually by a speaker } \\
\text { from another university }\end{array}$ \\
\hline 3 & Building student motivation & $\begin{array}{l}\text { In person workshop facilitated by a speaker } \\
\text { from another university }\end{array}$ \\
\hline 4 & $\begin{array}{l}\text { Evaluating student } \\
\text { knowledge }\end{array}$ & Facilitated faculty reading + discussion group \\
\hline
\end{tabular}

The topic for Workshop 1 was on both the use of technology in classroom innovation and active learning. The discussion in this workshop was motivated by the overall question, "who is at the center of the classroom," with the overall goal of aligning class learning objectives with instruction. The facilitators for the workshop provided a wealth of resources, both literature- and technology-based, that are available on- and off-campus to participants. As two examples of this, Chickering's principles for interactions between faculty and students were introduced [24], and the tool Poll Everywhere was presented as a way to elicit muddiest points from students. This workshop was attended by 12 participants.

Workshop 2 focused on active learning and classroom management. In this workshop, the facilitator introduced topics such as how to breakdown a large topic into small portions, keeping in mind the retention-versus-time curve. The facilitator led by example, allowing participants to choose which topics to focus on that day through an online voting tool. The topics selected were: jigsaw activities, device-enabled active learning, and problem/project/product-based learning (PBL). This workshop was attended by 13 participants.

Workshop 3 was a presentation on building student motivation. Drawing from motivational theories commonly used in education, the facilitator showed the motivation spectrum and discussed issues around autonomy and relatedness. The facilitator then led the participants through an active exercise on how to change student behavior in the class to become more motivated. This workshop was attended by 8 participants.

The topic for workshop 4 was evaluating student knowledge. For this workshop, the participants were asked to read specific sections from the Felder and Brent book [19]. The format of this workshop was faculty discussion-led, where participants shared their experiences as they related to the reading. This workshop was attended by 4 participants.

All content provided during the workshops was shared with participants afterwards so that they could reference it in the future and for the next phase of the program - the hackathon. Overall, the workshops, as the Sharing and Learning phase of the additive innovation cycle, provided participants with a wealth of information combined with new perspectives about teaching and learning. Olivia, for example, provided the following feedback: "I've been real (sic) excited by it. They've given me a wealth of ideas, so many that I having to narrow it down as to what could I 
do with this, but [it] seems like my mind is constantly thinking, 'Huh, what can I use here?' So I'm excited about it." Alexander commented that, "I like it because [...] it's very interesting to go through the material that we've covered so far and hear how peers not just in my program, but peers in other programs, do things because I'm really on the lookout for new ideas and trends and pedagogies that are more successful."

\section{$\underline{\text { Teaching Hackathon (October) }}$}

The third phase of the additive innovation cycle, Iterating on Designs, took the format of a teaching hackathon wherein the participants worked on a new pedagogical innovation of their choosing. Hackathons were originally conceived of in the domain of programming [25] and digital innovation as "a problem-focused computer programming event, as well as a contest to pitch, program, and present instances of prototype digital innovation." [26] While typically a hackathon lasts for several days, this event was limited to four and a half hours per session, which is still a great time commitment given the faculty's busy schedules.

In the weeks prior to the hackathon, participants were encouraged to recruit students and colleagues to the event, to diversify the experiences and perspectives they would have available to draw from and broaden the idea pool. (The research team similarly invited students and faculty who they thought would be interested and willing to provide feedback.) Participants were also asked to bring a curriculum module, textbook, laptop, and any other resources that would aid in formulating a new pedagogical innovation. At the end of the hackathon, participants demonstrated their new pedagogical innovations to each other. Two hackathons took place one week apart, with participants asked to attend at least one. Ten participants attended the first hackathon, and six attended the second, with one faculty member choosing to attend both events.

A key lesson from the event was that the concept of a teaching hackathon as lasting for a long time and involving multiple participants coming together to collaborate is new to some faculty members. It is therefore necessary to provide orientation to the event upfront. The research team facilitated the hackathon, explaining the purpose of the hackathon as dedicated time for the participants to work and enact change in their classes, giving guidance on how teams should work, and encouraging inter-team feedback and interactions. Participants were also given the chance to choose their hub, i.e., their working place for the long period of the hackathon, and they were encouraged to change or modify the workplace as they saw fit. Participant Ed commented on his experience, trying to find the material for his innovation during the constrained time of the hackathon saying that he "was trying to get to a point where I could present it by the end of the day." Participant Betty provided the following perspective on the hackathon: "Even the projects that other people were working on [...] was really helpful for me to hear."

\section{Community building happy hours (November)}

Also, as part of the third phase of the additive innovation cycle, participants were invited to attend optional, informal community building gatherings. These events took place off-campus, with attendance ranging between three to six participants. The month of November was generally a busy time for the faculty, especially since it was the time when most participants were 
implementing their planned innovations. These events were largely meant to help bond participants as members of a community, as they could attend.

\section{Story crafting workshop (December)}

The final phase of the Pedagogical Ninjas program, Sharing Innovations, required participants to record a video documenting their journey in the program through a storytelling format. Each participant shared their pedagogical innovation as it evolved from the beginning of the program to its final implementation and their reactions to the process. In order to help each participant craft their story, a workshop facilitated by the research team took place a few days prior to the recording. The workshop introduced the participants to the importance of stories, their structure, as well as one common and effective way to build a story. Stories would follow a simplified version of Campbell's Hero's Journey structure [27]: departure, difficulty/discovery, and return. Participants were asked to map their journey through the different stages on design worksheets. Then, they were asked to verbalize the elements of the story to a colleague in a timed practice, revise their story, and try it again. This iterative process prepared the participants to be ready when the actual recording took place. At the end of the workshop, the Pedagogical Ninjas shared their stories with the larger group. Video recording of each participant's story took place later in the week. These videos are currently being edited and will be shared using a suitable platform to act as a seed for future pedagogical innovations, completing the additive innovation cycle.

\section{Lessons Learned}

The Pedagogical Ninjas program was a new intervention aimed at inspiring faculty to adopt a pedagogical risk-taking mindset and develop new innovations for the classroom using an additive innovation framework. Table 4 below summarizes this change as an outcome of the program. Many of the participants expressed satisfaction with the program with interest in its continuation as a community building program. The research team had several key takeaways throughout the study related to the importance of upfront planning, the recruitment of participants, the implementation of program activities, and the balancing of collegiality with research objectivity. We offer the following lessons and recommendations for implementing similar programs or events at other institutions:

- Careful upfront planning: We started designing the Pedagogical Ninjas program early in the summer before its launch. To allow the research team time for thoughtful planning, we held half-day meetings at an off-campus location several times during the summer. Upfront planning was particularly important in creating a schedule for the program that could be advertised as part of our recruitment materials, as most participants would soon be planning their courses for the new semester. While some participants were comfortable implementing an innovation in-situ without advanced planning, others saw participation in the program as potentially influencing their course flow and wanted time to plan ahead. Delaying sharing basic information about the program, such as the time commitment and start date, would have prevented a sufficient number of participants from joining the program, thereby, potentially limiting its impact. 
Table 4. Change in participants' planned innovations between start and end of program.

\begin{tabular}{|c|c|c|c|}
\hline $\begin{array}{l}\text { Participant } \\
\text { (Pseudonym) }\end{array}$ & $\begin{array}{l}\text { Teaching } \\
\text { domain }\end{array}$ & Initial plans & Final implementation \\
\hline Alexander & Entrepreneurship & Online learning & Use of online polling \\
\hline Betty & Graphics & Assessment & $\begin{array}{l}\text { Replacing final exam with } \\
\text { a game }\end{array}$ \\
\hline Craig & Automotive & Engaging slide content & $\begin{array}{l}\text { Storytelling, active } \\
\text { engagement }\end{array}$ \\
\hline Derek & Media & [Nothing specific] & Online polling \\
\hline $\mathrm{Ed}$ & Graphics & $\begin{array}{l}\text { Undergraduate teaching } \\
\text { assistants, or live feedback }\end{array}$ & $\begin{array}{l}\text { Change of class material } \\
\text { (presentation) }\end{array}$ \\
\hline Felicia & Programming & Online learning & $\begin{array}{l}\text { Online interaction between } \\
\text { students }\end{array}$ \\
\hline Griffin & Design & Online voting & $\begin{array}{l}\text { Changing one assignment } \\
\text { (remove redundant } \\
\text { problem and introduce new } \\
\text { one) }\end{array}$ \\
\hline Hannah & Graphics & Polling tools & $\begin{array}{l}\text { Reimagining a final project } \\
\text { (defining expectations and } \\
\text { outcomes more clearly) }\end{array}$ \\
\hline Ian & Economics & Storytelling & Online polling \\
\hline Julia & Design & Incorporating technology & $\begin{array}{l}\text { Adding a new activity } \\
\text { (working hands-on with } \\
\text { motors) }\end{array}$ \\
\hline Kayla & Photography & [Nothing specific] & $\begin{array}{l}\text { Incorporating software for } \\
\text { reflection assignment }\end{array}$ \\
\hline Lucas & Graphics & Online engagement & $\begin{array}{l}\text { Change of an assignment } \\
\text { to become a jigsaw activity } \\
\text { (options in functions of } \\
\text { software) }\end{array}$ \\
\hline Matt & Environmental & Modifying slide content & $\begin{array}{l}\text { Final exam preparation } \\
\text { game }\end{array}$ \\
\hline Nate & Entrepreneurship & $\begin{array}{l}\text { In-class engagement } \\
\text { strategies }\end{array}$ & Online polling \\
\hline Olivia & Air traffic control & Modifying slide content & $\begin{array}{l}\text { Interactive jigsaw activities } \\
\text { (exploring topics from the } \\
\text { Air Traffic Control } \\
\text { Handbook) }\end{array}$ \\
\hline
\end{tabular}

- Recruitment of participants: The process of participant recruitment started in the summer of 2018. As described before (under Initial planning), we utilized customer discovery interviews with potential participant to understand their needs. These informal discussions provided useful insights into the perspectives and motivations of non-tenure track faculty members and were essential to designing a program that met their needs, instead of assuming what they needed or what they would respond to from the view of 
professional development. We also found it necessary in the recruitment process to expand our search for participants beyond typical engineering programs, due to sample size concerns. In addition to engineering lecturers and professors of practice, we recruited non-engineering faculty members whose teaching domains still overlapped with STEM, such as graphic information technology and aviation technology. This ultimately ended up serving the program well by infusing ideas to create innovation from many different technical disciplines.

- Implementation of program activities: As this was the research team's first attempt at delivering such a program, we were faced with both logistical and programmatic challenges. Logistically, finding a time for fifteen faculty members to join events was challenging. Fortunately, all participants were available on Friday afternoons, with some rescheduling personal commitments in order to attend, indicating a clear interest in the events that were taking place. Programmatically, some of the ideas were new to some faculty members. The teaching hackathon, for example, was a new kind of event for a significant number of participants. Elsewhere in the program, a few of the workshop speakers delivered lecture-style talks with limited hands-on activity, which some participants did not find insightful. Going forward, we might suggest implementing fewer activities with a smaller number of participants to help with scheduling difficulties; institutions could also offer any one of the activities described in this paper at scale. We also suggest making clear expectations for all parties involved in the program, ahead of time, to help ensure that participants have the most satisfactory experience in the program as possible.

- Sustainability considerations: With the participants completing all the phases of the additive innovation cycle, the interest to engage in another cycle illustrates the impact of the Pedagogical Ninjas program on the faculty's interest in risk taking. For the new implementation cycle, and in light of some of the guiding principles proposed in [2], we observe the importance of motivating the autonomy of participants to engage with the community. This could be achieved by allowing participants to take some ownership over the programming of events. Also, challenges may surface in future implementations around funding; therefore, creative ways for recognition and incentives should be provided.

\section{Future Work}

Analysis of the data collected from participants throughout the program is ongoing. A multiple case study research method is being employed to investigate the effectiveness and impact of the Pedagogical Ninja program, and specifically, how participation in each stage of the additive innovation cycle influences faculty practices and intentions related to pedagogical risk-taking. We will use logic models as an analytic technique to describe and compare the experiences of individual participants, whom we define as our unit of analysis. Findings from this work are expected to help determine how administrative structures can support faculty as agents of change. This research will also contribute to an understanding of how embracing a mindset of additive innovation and pedagogical risk-taking as a faculty member can lead to desired professional competencies among engineering students. 


\section{References}

[1] S. Jordan and M. Lande, "Additive innovation in design thinking and making," International Journal of Engineering Education, vol. 32, no. 3, pp. 1438--1444, 2015.

[2] J. Bekki, A. Ayela-Uwangue, S. Brunhaver, N. Kellam, M. Lande and A. McKenna, "I Want to Try That Too! Development of a Conceptual Framework for Interventions that Encourage Pedagogical Risk-Taking Among Faculty," in Proceedings of the American Society for Engineering Education Conference, 2017.

[3] T. K. Grose, "Hardy Perennials: As Engineering Education Advanced Through the Decades, Key Debates Kept Recurring," ASEE Prism, vol. 22, no. 9, p. 34-38, Summer 2013.

[4] NAE, "The Engineer of 2020," National Academies Press, Washington, D.C., 2004.

[5] Committee, "Charting a course for success: America's strategy for STEM education," Committee on STEM Education of the National Science: National Science \& Technology Council, Washington, D.C., 2018.

[6] R. Felder, R. Brent and M. Prince, "Engineering Instructional Development: Programs, Best Practices, and Recommendations," Journal of Engineering Education, vol. 100, no. 1, p. 89-122, 2011.

[7] A. Kezar, "The Path to Pedagogical Reform in the Sciences: Engaging Mutual Adaptation and Social Movement Models of Change," Liberal Education, vol. 98, no. 1, pp. 40-45, 2012.

[8] P. J. Palmer, "Divided No More: A Movement Approach to Educational Reform," Change: The Magazine of Higher Learning, vol. 24, no. 2, pp. 10-17, 1992.

[9] W. Watson and S. Watson, "Exploding the Ivory Tower: Systemic Change for Higher Education," TechTrends, vol. 57, no. 5, pp. 42-46, 2013.

[10] A. Bromage, "The Management of Planned Change: An Interdisciplinary Perspective," in The Realities of Change in Higher Education: Interventions to Promote Learning and Teaching, New York, NY, Routledge, 2006, pp. 1-14.

[11] R. Zemsky, Making Reform Work: The Case for Transforming American Higher Education, Piscataway, NJ: Rutgers University Press, 2009.

[12] H. Matusovich, M. Paretti, L. McNair and C. Hixson, "Faculty motivation: A gateway to transforming engineering education," Journal of Engineering Eucation, vol. 103, no. 2, pp. 302-330, 2014.

[13] R. Barr and J. Tagg, "From Teaching to Learning: A New Paradigm for Undergraduate Education," Change, vol. 27, no. 6, pp. 12-25, 1995.

[14] P. Baker, "Creating Learning Communities: The Unfinished Agenda," in The Social Worlds of Higher Education: Handbook for Teaching in a New Century, Thousand Oaks, CA, Pine Forge Press, 1999, pp. 95-109. 
[15] C. Henderson, A. Beach and N. \& Finkelstein, "Four Categories of Change Strategies for Transforming Undergraduate Instruction," in Transitions and Transformations in Learning and Education, New York, NY, Springer, 2012, pp. 223-245.

[16] D. Johnson, R. Johnson and K. Smith, "Cooperative Learning Returns To College What Evidence Is There That It Works?," Change: The Magazine of Higher Learning, vol. 30, no. 4, pp. 26-35, 1998.

[17] M. Prince, "Does Active Learning Work? A Review of the Research," Journal of Engineering Education, vol. 93, no. 3, pp. 223-231, 2004.

[18] L. Jamieson and J. Lohmann, "Creating a Culture for Scholarly and Systematic Innovation in Engineering Education," American Society for Engineering Education, Washington, D.C., 2009.

[19] W. Booth, G. Colomb and J. M. Williams, The craft of research, University of Chicago Press, 2008.

[20] G. Constable, Talking to Humans: Success starts with understanding your customers, Giff Constable, 2014.

[21] NSF, "Innovation Corps - National Innovation Network Teams Program (I-CorpsTM Teams)," National Science Foundation, [Online]. Available: https://www.nsf.gov/funding/pgm_summ.jsp?pims_id=504672. [Accessed March 2019].

[22] S. Blank, "The Lean LaunchPad: Teaching Entrepreneurship as a Management Science," Steve Blank, 7 December 2010. [Online]. Available: https://steveblank.com/2010/12/07/the-lean-launchpad-\%E2\%80\%93-teachingentrepreneurship-as-a-management-science/. [Accessed March 2019].

[23] R. K. Yin, Case study research: Design and methods, Thousand Oaks, CA: Sage Publications, Inc., 2003.

[24] A. Chickering and Z. Gamson, "Seven Principles for Good Practice in Undergraduate Education," The Wingspread Journal, vol. 9, no. 2, 1987.

[25] H. Topi and A. Tucker, Computing Handbook: Information Systems and Information Technology, Third Edition ed., CRC Press, 2014.

[26] G. Briscoe and C. Mulligan, "Digital innovation: The hackathon phenomenon," 2014.

[27] J. Campbell, The Hero with a Thousand Faces, 3rd ed., Novato, CA: New World Library, 2008.

[28] NSB, "Moving forward to improve engineering education," National Science Board, 2007. 